\title{
Evasão escolar nos cursos técnicos integrados ao ensino médio da Rede Federal: Levantamento de fatores motivacionais e propostas de intervenção
}

\author{
School dropout in technical courses integrated to the Federal Network high school: Survey of \\ motivational factors and intervention proposals
}

Evasión escolar en cursos técnicos integrados a la Red Federal bachillerato: Encuesta de factores motivacionales y propuestas de intervención

Recebido: 30/04/2021 | Revisado: 06/05/2021 | Aceito: 09/05/2021 | Publicado: 22/05/2021

Karine Rodrigues Alvarez
ORCID: https://orcid.org/0000-0003-3058-3641
Instituto Federal de Educação, Ciência e Tecnologia de Minas Gerais, Brasil
E-mail: karine.alvarez@ifmg.edu.br
Suelem Cristina Alves
ORCID: https://orcid.org/0000-0001-6335-0006
E-mail: suelem.alves@ifmg.edu.br
Roberta Pereira Matos
Instituto Federal de Educação, Ciência e Tecnologia de Minas Gerais, Brasil
ORCID: https://orcid.org/0000-0003-0481-9710
Instituto Federal de Educação, Ciência e Tecnologia do Norte de Minas Gerais, Brasil
E-mail: roberta.matos@ @ifnmg.edu.br

\begin{abstract}
Resumo
Verificou-se neste artigo como o fenômeno da evasão escolar tem sido desvelado no âmbito da Rede Federal de Educação Profissional, Científica e Tecnológica. No estudo de caráter qualitativo, utilizou-se a pesquisa bibliográfica e documental para subsidiar a construção de um panorama de estudos sobre a problemática. Os resultados apontaram que os pesquisadores conceituaram a evasão escolar como a perda de vínculo entre aluno e Instituição de ensino. Os fatores motivacionais identificados como promotores da evasão escolar foram: falta de adaptação à vida acadêmica, desencanto ou desmotivação com o curso escolhido, pouca capacidade de aprendizagem e habilidade de estudo, questões didático-pedagógicas, gestão acadêmica do curso e conjuntura econômica e social. As propostas de intervenção se apresentaram por meio de ações de acolhida direcionada aos discentes ingressantes e acompanhamento do desempenho escolar. Pode-se concluir que os diagnósticos dos fatores motivacionais da evasão escolar se fazem necessários para mitigar seus efeitos, assim como direcionar a construção de propostas de intervenção.
\end{abstract}

Palavras-chave: Evasão escolar; Ensino médio integrado; Rede federal.

\begin{abstract}
It was found in this article how the phenomenon of school dropout has been unveiled within the scope of the Federal Network of Professional, Scientific and Technological Education. In the qualitative study, bibliographic and documentary research was used to support the construction of a panorama of studies on the problem. The results showed that the researchers conceptualized school dropout as the loss of link between student and educational institution. The motivational factors identified as promoters of school dropout were: lack of adaptation to academic life, disenchantment or demotivation with the chosen course, poor learning capacity and study skills, didacticpedagogical issues, academic management of the course and economic and social context. The intervention proposals were presented through welcoming actions directed to incoming students and monitoring of school performance. It can be concluded that diagnoses of motivational factors for school dropout are necessary to mitigate their effects, as well as direct the construction of intervention proposals.
\end{abstract}

Keywords: School dropout; Integrated high school; Federal network.

\section{Resumen}

En este artículo se verificó cómo se ha develado el fenómeno de la deserción escolar en el ámbito de la Red Federal de Educación Profesional, Científica y Tecnológica. En el estudio cualitativo se utilizó la investigación bibliográfica y documental para apoyar la construcción de un panorama de estudios sobre el problema. Los resultados mostraron que los investigadores conceptualizaron la deserción escolar como la pérdida del vínculo entre el estudiante y la institución educativa. Los factores motivacionales identificados como promotores de la deserción escolar fueron: falta de adaptación a la vida académica, desencanto o desmotivación con el curso elegido, poca capacidad de aprendizaje y habilidades de estudio, aspectos didáctico-pedagógicos, gestión académica del curso y contexto económico y social. 
Las propuestas de intervención se presentaron a través de acciones de acogida dirigidas a los alumnos entrantes y seguimiento del desempeño escolar. Se puede concluir que los diagnósticos de factores motivacionales del abandono escolar son necesarios para mitigar sus efectos, así como orientar la construcción de propuestas de intervención.

Palabras clave: Abandono escolar; Escuela secundaria integrada; Red federal.

\section{Introdução}

Os primeiros estudos sobre evasão escolar no Brasil, datados nos anos 80 , foram realizados por interesse do Ministério da Educação (MEC) e de Universidades públicas. Eram estruturados por meio de estudos de casos segmentados, abordavam levantamentos estatísticos e possíveis motivações, sem indicar caminhos para superação do problema. Foi no início dos anos 90 que as pesquisas começaram a adquirir outros formatos traçando um horizonte para estudos sistematizados. Esse formato de estudo surgiu em meio às discussões de elaboração de indicadores de avaliação, definidos pelo Programa de Avaliação Institucional das Universidades Brasileiras, e deram origem a Comissão Especial para o Estudo da Evasão nas Universidades Brasileiras (Brasil, 2014).

Essa Comissão foi responsável por estabelecer um parâmetro para os estudos ao desmitificar o conceito de evasão escolar, definindo-o como a "saída definitiva do aluno de seu curso de origem, sem concluí-lo" (Brasil, 1996a, p. 15). Antes desse parâmetro, as pesquisas utilizavam diferentes interpretações sobre a evasão, tais como evasão da Instituição, do sistema de ensino ou do curso, e isto impactava a forma de cálculo e impedia análises comparativas. Essas diretrizes possibilitaram explorar as nuances do fenômeno para além de dados quantitativos e padronizar uma metodologia para o uso das Instituições.

Esse contexto, de avaliações e discussão de indicadores, se assemelha ao marco teórico dos estudos sistematizados sobre evasão escolar no âmbito da Rede Federal de Educação Profissional, Científica e Tecnológica (Rede Federal). Visto que os estudos decorrem em resposta ao Acórdão n 506 de 2013, publicado pelo Tribunal de Contas da União (TCU) (Brasil, 2013; 2014), após auditoria com vistas a garantir parâmetros de qualidade na oferta da educação. Nesse documento, o TCU recomendou o desenvolvimento de ações para melhoria das estruturas da Rede Federal mediante o processo de expansão.

Segundo o MEC, no processo de expansão da Rede Federal, muitos foram os desafios que se apresentaram na oferta de "educação com qualidade num processo de inclusão socioprofissional e educacional" frente às diferenças regionais, locais e diversidade do público (Brasil, 2014, p. 11). Dentre esses, sobressaem-se as elevadas taxas de evasão escolar identificados, nos anos de 2011/2012, após a consolidação das fases I e II de expansão da Rede Federal (Brasil, 2013).

Em decorrência desses fatos, o MEC instituiu um Grupo de Trabalho para levantar as causas da evasão e retenção, e elaborar um manual de orientação para o combate e controle desses fenômenos. O resultado surgiu em 2014 com a publicação do "Documento orientador para a superação da evasão e retenção na Rede Federal de Educação Profissional, Científica e Tecnológica" (Brasil, 2014). Esse documento buscava incentivar o acompanhamento das taxas de retenção e evasão e implementar planos de ações de enfrentamento a esses fenômenos. Em 2015 o MEC ratificou essas orientações com a divulgação da "Nota Informativa 138", direcionando as unidades da Rede Federal a criarem Planos Estratégicos Institucionais de Permanência e Êxito dos Estudantes. Os objetivos propostos eram diminuir os índices de evasão e retenção dos alunos, promover ações que garantissem à democratização do acesso à educação e fortalecer a atuação Institucional (Brasil, 2015).

Essas premissas despertaram o interesse das autoras para investigar a temática da evasão escolar no âmbito da Rede Federal, assim como verificar no meio acadêmico a existência de pesquisas que abordem o assunto, destacando o marco temporal de 2015 a 2019, já que este recorte corresponde ao período posterior às diretrizes do MEC para o acompanhamento das taxas de evasão e promoção de intervenções que visassem a garantia da democratização do acesso à educação.

Além disso, delimitou-se a análise a partir de trabalhos que tiveram como objeto de estudo os cursos técnicos integrados ao ensino médio (cursos integrados) ofertados presencialmente. Isto porque, conforme determinação legal, no mínimo 50\% das vagas ofertadas nos Institutos Federais devem ser destinadas aos cursos integrados (Brasil, 2008), logo, 
presume-se que essa delimitação é representativa na Rede Federal. Definiu-se como objetivo deste artigo analisar os trabalhos de pós-graduação stricto sensu que abordam o fenômeno da evasão escolar e apresentam diagnósticos com os fatores motivacionais da evasão e respectivas propostas de enfrentamento. Acredita-se que os trabalhos podem indicar como a problemática tem sido desvelada nos cursos da Rede Federal e conduzir as demais Instituições a refletirem sobre suas práticas.

\section{Metodologia}

Com abordagem qualitativa, adotou-se no delineamento deste estudo a coleta de dados secundários, por meio da pesquisa bibliográfica e documental, sendo o principal objetivo desvelar, a partir das pesquisas acadêmicas, o fenômeno da evasão escolar no âmbito da Rede Federal.

Martins e Theóphilo (2016) destacam que nas pesquisas deste tipo busca-se conhecer, analisar e explicar contribuições sobre determinado assunto, tema ou problema. Tendo em vista que a pesquisa bibliográfica é realizada com base no material já publicado, a revisão bibliográfica tem o propósito de fornecer fundamentação teórica ao trabalho, bem como identificação do estágio atual do conhecimento referente ao tema (Gil, 2010, p. 29).

Neste sentido, realizou-se a coleta de dados no primeiro semestre de 2020 por meio do levantamento de trabalhos de pós-graduação stricto sensu disponíveis no "Catálogo de Teses e Dissertações" da Coordenação de Aperfeiçoamento de Pessoal de Nível Superior (CAPES). Utilizou-se como palavra-chave, na busca dos trabalhos, o termo "ensino médio integrado" juntamente com o filtro de publicações por ano "2015 a 2019".

O primeiro resultado apresentou 337 (trezentas e trinta e sete) pesquisas. Essas possuíam diversas temáticas como: currículo, histórico de implementação do ensino integrado na Rede Federal, atuação docente e práticas de ensino nos cursos integrados, dentre outras. Além disso, havia estudos realizados em diversas Instituições, sendo estas da rede pública e privada, bem como nas esferas municipal, estadual e federal. Dessa forma, foi preciso realizar a primeira análise do objeto deste estudo buscando, por meio da leitura do título e das palavras-chave, trabalhos que enfatizassem a temática evasão escolar nas Instituições da Rede Federal. Posto isto, selecionou-se 67 (sessenta e sete) trabalhos que tratavam da evasão na Rede Federal.

Tendo em vista o objetivo e a delimitação desse estudo, realizou-se uma nova seleção de trabalhos a partir da leitura dos resumos, resultados e conclusão das pesquisas. Na verificação desses requisitos, obteve-se 8 (oito) trabalhos, no formato de dissertações, não sendo encontrada nenhuma tese.

Procedeu-se então para leitura minuciosa dos trabalhos com vistas a se identificar os elementos que caracterizavam a investigação e que fossem relevantes para este estudo. Para categorizar e analisar os dados, considerou-se o "Documento orientador para superação da evasão e retenção" (Brasil, 2014), indicando os fatores individuais, internos e externos à Instituição de ensino como motivadores da evasão escolar, e a "Nota Informativa 138" (Brasil, 2015), indicando o cunho pedagógico ou administrativo das propostas de intervenção.

\footnotetext{
${ }^{1}$ Disponível em: <http://catalogodeteses.capes.gov.br/catalogo-teses/\#!/>. Acesso em: 13 jan. 2020.
} 


\section{Resultados e Discussão}

Para fins de cálculos da evasão escolar o MEC considera o status da matrícula, indicado por meio do Sistema Nacional de Informações da Educação Profissional e Tecnológica, levando em conta que: “a evasão decorre do desligamento do estudante de um curso, caracterizada em diversas situações, tais como: abandono, pedido de cancelamento de matrícula, transferência interna ou externa" (Brasil, 2015, p. 2).

Essa definição se apresenta por meio de fases a partir de dois status: matrícula ativa, identificada no início do curso, e matrícula finalizada, identificada após o encerramento de todas as etapas da formação. Na amplitude desses status podem ocorrer situações que caracterizam a evasão escolar conforme entendimento do MEC. Tais aspectos interferem na amostragem e cálculos dos estudos, considerando que a evasão pode ser interpretada por meio do período ou do ciclo:

Os indicadores relativos ao período são relevantes para a avaliação sistêmica das instituições e das redes de ensino, inclusive para relatórios anuais de gestão, porque medem o resultado obtido com os recursos destinados ao trabalho institucional e apresentam o desempenho do conjunto geral de matriculados em relação à expectativa de sucesso daqueles que ingressaram. As taxas no ciclo permitem observar o desempenho de um determinado grupo de ingressantes de um determinado tipo de curso e com isso associar outros fatores à análise (econômicos, sociais etc.). Por outro lado, não permitem a avaliação sistêmica, pois para realizar a análise dos ciclos, se faz necessário definir o conjunto a partir do critério "período de estimativa de finalização". Dessa forma, acabam sendo desconsideradas todas as matrículas que eventualmente concluíram ou abandonaram no período, mas são ingressantes de outros ciclos que não se enquadram no critério (Brasil, 2014, p. 24-25).

$\mathrm{Na}$ investigação por período a amostra é determinada pelos dados da matrícula ou dos alunos matriculados, permitindo o agrupamento de informações e o acompanhamento das taxas de evasão e índices de conclusão de cursos a cada período de alteração no status da matrícula. Sendo a fórmula de cálculo definida por "Taxa de evasão no período = estudantes que tiveram a matrícula finalizada sem êxito / estudantes com matrícula ativa” (Brasil, 2014, p. 24). A amostragem, na investigação por ciclo, advém do grupo de ingressantes ou concluintes com características específicas, podendo realizar o recorte da amostra por cursos, eixos, modalidade de ingresso, dentre outros. A fórmula de cálculo é definida por "Taxa de evasão do ciclo = estudantes que tiveram a matrícula finalizada sem êxito no ciclo / ingressantes do ciclo” (Brasil, 2014, p. 25).

Os tópicos aqui apresentados reforçam a importância da delimitação do campo de estudo, da caracterização da amostragem investigada, bem como dos conceitos adotados para se realizar a análise do fenômeno da evasão escolar.

Dore e Lüscher (2011) apresentam, a partir de Jordan, Lara e McPartland (1996c), três dimensões conceituais necessárias à compreensão do fenômeno: o nível de escolaridade em que ele ocorre; o tipo de evasão identificado e os motivadores da evasão. O nível diz respeito à obrigatoriedade ou não do ensino, bem como a universalização da oferta de vagas. O tipo de evasão tem relação com a possibilidade de retomada dos estudos, já os motivadores são caracterizados pela justificativa da evasão. Dessa forma, entende-se que a acessibilidade e oferta do curso também interferem na caracterização do processo de evasão escolar, visto que influencia a forma e o momento no qual se ocorre a evasão.

$\mathrm{Na}$ primeira análise das dissertações, observa-se a predominância do gênero feminino na autoria de sete dos oito trabalhos. As produções decorrem de programas ofertados em Instituições públicas das áreas de educação e gestão. As pesquisas adotaram o entendimento da evasão escolar proposto pelo MEC considerando os status da matrícula "finalizada sem êxito". Assim, os cálculos das taxas de evasão escolar consideraram a amostragem por período ou ciclo, conforme Tabela 1 . 
Tabela 1 - Caracterização da amostragem e taxas de evasão escolar identificados nas dissertações ${ }^{2}$.

\begin{tabular}{|c|c|c|c|c|c|}
\hline Autor & Análise & Amostra & Cursos analisados & Instituição & $\begin{array}{l}\text { Taxas de } \\
\text { evasão }\end{array}$ \\
\hline $\begin{array}{l}\text { Souza } \\
(2015) \\
\end{array}$ & Período & $\begin{array}{c}\text { Concluintes } \\
\text { em } 2014 .\end{array}$ & Informática, Eletrônica, Comércio. & IFTM - campus Paracatu. & $14,91 \%$ \\
\hline $\begin{array}{l}\text { Veiga } \\
(2016)\end{array}$ & Ciclo & $\begin{array}{l}\text { Ingressantes } \\
2013-2015 .\end{array}$ & $\begin{array}{l}\text { Infraestrutura, Ambiente e saúde, } \\
\text { Controle e processos industriais, } \\
\text { Segurança, gestão e negócios, } \\
\text { Informática e comunicação, Turismo, } \\
\text { hospitalidade e lazer }{ }^{3} \text {. }\end{array}$ & $\begin{array}{l}\text { CEFET - RJ UnED } \\
\text { Maracanã. }\end{array}$ & $26 \%$ \\
\hline $\begin{array}{l}\text { Dourado } \\
(2016)\end{array}$ & Período & $\begin{array}{l}\text { Concluintes } \\
\text { em } 2016 .\end{array}$ & $\begin{array}{l}\text { Biocombustíveis, Eletromecânica, } \\
\text { Informática. }\end{array}$ & $\begin{array}{l}\text { IFBA - campus de } \\
\text { Irecê/Bahia }\end{array}$ & $\begin{array}{l}68 \%-2011 \\
66 \%-2012 \\
60 \%-2013 \\
50 \%-2014 \\
\end{array}$ \\
\hline $\begin{array}{l}\text { Santos } \\
\text { (2017) }\end{array}$ & Ciclo & $\begin{array}{l}\text { Ingressantes } \\
\text { em } 2013 .\end{array}$ & $\begin{array}{l}\text { Edificaçõos, Informática, } \\
\text { Meio Ambiente. }\end{array}$ & IFBA - campus Eunápolis & $57,6 \%$ \\
\hline $\begin{array}{l}\text { Medeiros } \\
(2018)\end{array}$ & Ciclo & $\begin{array}{l}\text { Ingressantes } \\
\text { em } 2013 .\end{array}$ & $\begin{array}{l}\text { Agropecuária, Edificações, } \\
\text { Informática. }\end{array}$ & $\begin{array}{c}\text { IF do Sertão } \\
\text { Pernambucano - campus } \\
\text { Ouricuri - PE }\end{array}$ & $70 \%$ \\
\hline $\begin{array}{l}\text { Feitosa } \\
(2018)\end{array}$ & Período & $\begin{array}{c}\text { Matrículas } \\
\text { ativas em } \\
2018 . \\
\end{array}$ & Logística, Edificações. & $\begin{array}{c}\text { IF do Sertão } \\
\text { Pernambucano - campus } \\
\text { Serra Talhada } \\
\end{array}$ & $9,6 \%$ \\
\hline $\begin{array}{l}\text { Almeida } \\
(2019)\end{array}$ & Período & $\begin{array}{c}\text { Concluintes } \\
\text { em } 2017 . \\
\end{array}$ & $\begin{array}{l}\text { Edificações, Informática, } \\
\text { Química. }\end{array}$ & IFG - campus Uruaçu & $39,6 \%$ \\
\hline $\begin{array}{l}\text { Rosales } \\
(2019)\end{array}$ & Período & $\begin{array}{l}\text { Matrículas } \\
\text { ativas em } \\
2018-2019 .\end{array}$ & $\begin{array}{l}\text { Automação Industrial, } \\
\text { Controle Ambiental, Informática. }\end{array}$ & IFSul - campus Camaquã. & $9,3 \%$ \\
\hline
\end{tabular}

Fonte: Autoras (2020).

Nota-se que as pesquisas utilizaram o recorte temporal de 2011 a 2019; aquelas que adotaram a análise por ciclo utilizaram a amostragem de ingressantes; na análise por período utilizaram-se dados dos concluintes ou matriculados no ano investigado. As taxas de evasão apresentaram variações de $26 \%$ a $70 \%$ por ciclo e $9,3 \%$ a $68 \%$ na análise por período; resultaram na média de $51,3 \%$ na análise por ciclo e $39,8 \%$ na análise por período.

Segundo dados do TCU nos cursos integrados, ano base 2011, a taxa de conclusão era de 46,8\% na média nacional (Brasil, 2013). Atualmente, dados da Plataforma Nilo Peçanha (PNP), ano base 2019, indicam o percentual de 58,6\% na média nacional para a taxa de conclusão no ciclo dos cursos integrados. Referente às taxas de evasão nos eixos Infraestrutura e Informática e comunicação, apresenta-se o percentual de $8 \%$ na análise do período e 33\% no ciclo (Brasil, 2020a).

A partir das informações identificadas em Souza (2015), Veiga (2016) e Almeida (2019), presume-se uma melhora nas taxas de evasão tendo em vista que as pesquisas apresentaram baixos níveis de evasão na análise por ciclo ou na amostragem por concluintes, e desempenho superior à média nacional diagnosticada em 2011. Infere-se que, 8 (oito) anos após a Auditoria do TCU, ocorreram movimentações nas Instituições da Rede Federal que se converteram em melhores índices representados tanto nas pesquisas quanto nos dados da PNP.

Sobre a variação média entre as taxas de evasão por ciclo e período, suspeita-se que uma das causas possa ser a conclusão dos cursos para além da previsão mínima de formação, isto é, a existência de taxas de retenção. Visto que na análise por ciclo considera-se o período máximo de integralização do curso.

\footnotetext{
${ }^{2}$ Ressalta-se que nos estudos de Almeida (2019) e Rosales (2019) não havia o quantitativo de evadidos, dessa forma obteve-se os dados subtraindo o total de ingressantes por concluintes.

${ }^{3}$ A pesquisa de Veiga (2016) não apresentou a análise de cursos, mas de áreas pertencentes aos cursos ofertados na Instituição.
} 
Levando em conta que no processo de expansão da Rede Federal foi diagnosticada ausência ou insuficiência de Infraestrutura física e de pessoal para a execução dos cursos (Brasil, 2013), recomenda-se, para uma análise aprofundada das taxas, contextualizá-las de modo a verificar se existiam turmas integralizadas, ou seja, com condições de atender todas as etapas de formação para a conclusão com êxito.

A respeito dos fatores motivacionais da evasão, considerou-se que esses podem ser de ordem individual, interna e externa à Instituição (Brasil, 2014). Dessa forma, identificou-se nas pesquisas a existência de 16 (dezesseis) categorias que representam os fatores motivacionais da evasão escolar, representados na Tabela 2.

Tabela 2 - Fatores motivacionais da evasão escolar nos cursos integrados da Rede Federal.

\begin{tabular}{l|l|c}
\hline Aspectos & \multicolumn{1}{|c}{ Fatores motivacionais } & Frequência \\
\hline \multirow{5}{*}{ Individual } & Adaptação à vida acadêmica. & 7 \\
\cline { 2 - 3 } & Capacidade de aprendizagem e habilidade de estudo. & 4 \\
\cline { 2 - 3 } & Compatibilidade entre a vida acadêmica e as exigências do mundo do trabalho. & 2 \\
\cline { 2 - 3 } & Descoberta de novos interesses ou novo processo de seleção. & 1 \\
\cline { 2 - 3 } & Encanto ou motivação com o curso escolhido. & 6 \\
\cline { 2 - 3 } & Qualidade da formação recebida na escolar anterior. & 2 \\
\cline { 2 - 3 } & Questões de saúde do estudante ou de familiar. & 2 \\
\cline { 2 - 3 } Interno & Outras questões de ordem pessoal ou familiar. & 1 \\
\hline & Total de fatores individuais & 2 \\
\hline \multirow{5}{*}{} & Ftualização, estrutura e flexibilidade curricular. & 2 \\
\cline { 2 - 3 } & Gestão acadêmica do curso. & 6 \\
\cline { 2 - 3 } & Gestão administrativa e financeira da unidade de ensino. & 2 \\
\cline { 2 - 3 } & Infraestrutura física, material, tecnológica e de pessoal para o ensino. & 2 \\
\cline { 2 - 3 } & Questões didático-pedagógicas. & 6 \\
\cline { 2 - 3 } & Relação escola-família. & 2 \\
\hline
\end{tabular}

Fonte: Autoras (2020).

Sobre os fatores mais frequentes nas pesquisas, destacam-se nos aspectos individuais: dificuldade de adequação à rotina escolar, indisponibilidade de tempo para estudar fora do horário de aulas, medo de repetir o ano letivo, dificuldade de aprendizagem ou deficiência cognitiva e desinteresse ou falta de identificação com o curso. Nota-se que muitos desses fatores antecedem os processos de fracasso escolar, retenção e reprovação.

Almeida (2019), ancorada nas teorias de Bourdieu e Passeron (2008), constatou que o fracasso escolar tem relação com o capital cultural, logo, o êxito escolar é alcançado, principalmente, pelos indivíduos com habitus semelhante ao esperado pelo sistema escolar. E por isso, a análise do sucesso ou do fracasso escolar deve considerar as perspectivas do aluno, sua condição econômica ou familiar, assim como o sentido da escola no processo formativo do sujeito (Almeida, 2019, p. 47).

A respeito dessas condições, os resultados da pesquisa de Veiga (2016) vão ao encontro dessas premissas ao constatar que os fatores socioeconômicos interferem diretamente nas motivações da evasão escolar. O pesquisador chegou a esse resultado ao correlacionar os fatores que predominavam no diagnóstico realizado em seu estudo. Dessa forma, constatou que “dificuldades nos processos de aprendizagem” tem forte relação com vulnerabilidade socioeconômica, já "desinteresse próprio" aparece no grupo de alunos com maior poder aquisitivo e oriundos da rede privada de ensino.

Nos aspectos internos, os fatores recorrentes se apresentam por meio de dificuldades de relacionamento entre docentes e estudantes, inadequação da metodologia de ensino ao perfil dos estudantes, dificuldades de realização de aulas práticas, de 
estágio curricular, excesso de carga horária semanal de aulas, falta de integração curricular, inadequação da organização do ensino em ciclo bimestral, falta de acompanhamento e apoio pedagógico.

Sobre os aspectos internos à Instituição de ensino, Santos (2017) enfatiza que houve a democratização para a entrada de alunos, mas os processos internos da Instituição têm os conduzido à exclusão. Isso porque a pesquisadora constatou que a evasão ocorre em virtude da reprovação escolar, na qual o perfil do aluno excluído é majoritariamente de etnia negra e situação socioeconômica vulnerável, sendo as principais motivações para a evasão e reprovação escolar os fatores internos.

Essa constatação evidencia os apontamentos do MEC indicando que "compreender o significado da Rede Federal ainda se constitui em algo desafiador" tendo em vista que essa exclusão contradiz a proposta de "oportunizar o acesso à educação profissionalizante de maneira abrangente" (Brasil, 2014, p. 11-12).

Com relação ao aspecto externo, o único fator identificado se manifesta por meio de dificuldades de deslocamento ou relacionadas ao transporte; de condições de vulnerabilidade social, cultural e econômica do estudante e em decorrência da mudança de cidade ou de moradia. Essas motivações permeiam as questões de ordem material diretamente relacionadas à condição econômica e social dos sujeitos.

Souza (2015) se propôs a investigar esses aspectos a fim de identificar de que forma se dava a utilização da assistência estudantil e se esse benefício serviu de estímulo para a permanência dos alunos. Constatou-se que o auxílio estudantil "[...] produz no aluno o sentimento de independência, ou em outras palavras aumenta sua autonomia, pois ao possuir recursos para custear suas necessidades, o aluno passa a depender menos dos pais quanto ao aspecto financeiro" (Souza, 2015, p. 110). Isto porque, conforme revelado nas entrevistas, o benefício estudantil supria parte dos gastos estudantis como alimentação, transporte ou materiais para o estudo. Essa ajuda financeira permite que os discentes se concentrem nos demais aspectos da vida escolar, assim, pode-se considerar que a assistência estudantil se apresenta como ação promotora da permanência.

Observa-se que os fatores motivacionais da evasão se relacionam constantemente, sobretudo se considerarmos as questões do ambiente externo. Além disso, os resultados das pesquisas demonstram que os estudantes estão imersos a situações que dificultam sua trajetória escolar e a Instituição, no que lhe diz respeito, tende a reforçar ou evidenciar essas situações por meio de suas práticas e ritos. Assim, o processo de evasão, para além de levantamentos quantitativos, deve ser analisado sobre suas motivações. Estas são necessárias para se identificar quais práticas estão reforçando ou inibindo o vínculo Institucional.

Após o diagnóstico dos fatores motivacionais da evasão escolar, os pesquisadores apresentaram propostas de intervenção para mitigar seus efeitos, conforme Tabela 3. 
Tabela 3 - Resumo das propostas de intervenção apresentadas para reduzir a evasão.

\begin{tabular}{c|l|c}
\hline Categorias & \multicolumn{1}{|c}{ Intervenção } & Frequência \\
\hline \multirow{5}{*}{ Administrativa } & Aperfeiçoar a divulgação da Instituição e dos cursos. & 5 \\
\cline { 2 - 3 } & Ofertar capacitação para a comunidade escolar repensar suas práticas. & 4 \\
\cline { 2 - 3 } & Desenvolver banco de dados sobre o perfil dos discentes. & 3 \\
\cline { 2 - 3 } & Descentralizar o processo de seleção de professores substitutos. & 1 \\
\cline { 2 - 3 } & Expandir o atendimento da assistência estudantil. & 1 \\
\cline { 2 - 3 } & Implementar unidade de restaurante universitário. & 1 \\
\cline { 2 - 3 } & Monitorar a frequência dos alunos. & 1 \\
\hline \multirow{5}{*}{ Total de intervenções administrativas } & $\mathbf{1 6}$ \\
\hline \multirow{5}{*}{ Pedagógica } & Realizar acompanhamento e avaliação dos discentes. & 5 \\
\cline { 2 - 3 } & Desenvolver eventos internos para acolhida dos discentes. & 2 \\
\cline { 2 - 3 } & Implementar ações de reforço escolar. & 1 \\
\cline { 2 - 3 } & Divulgação de práticas exitosas. & 1 \\
\cline { 2 - 3 } & Estabelecer ações para o apoio pedagógico ao docente. & 1 \\
\cline { 2 - 3 } & Revitalizar o currículo escolar. & 1 \\
\cline { 2 - 3 } & Reduzir o tempo de curso para 3 (três) anos. & $\mathbf{1 4}$ \\
\hline
\end{tabular}

Fonte: Autoras (2020).

Sobre a frequência, identificou-se nas ações de cunho administrativo a predominância de propostas de divulgação da Instituição e dos cursos, a capacitação para a comunidade acadêmica e o desenvolvimento de banco de dados com as informações dos discentes. As ações pedagógicas enfatizaram ações de acolhida e de acompanhamento dos discentes, bem como a revisão do currículo e das práticas pedagógicas.

Observa-se que as propostas de intervenção buscam a ruptura das diferentes expectativas, quer seja do aluno, que precisa escolher precocemente uma profissão, quer seja da Instituição, que espera, no decorrer de três ou quatro anos, transpor as estruturas de desigualdades da sociedade. No percurso da trajetória escolar ocorrem situações que impactam no planejamento definido no ingresso à Instituição de ensino, e nem sempre é possível gerenciá-las a tempo de se conter os danos que motivam a evasão escolar.

A esse respeito, a pesquisa de Dourado (2016) identificou o período que ocorrem as evasões, sendo sua predominância no primeiro e último ano do curso. No primeiro ano as motivações se referem à adaptação do aluno à Instituição e ao curso. No último ano as motivações se referem às expectativas dos alunos quanto aos seus projetos para o futuro. Nesse caso, há um movimento de escolha entre tornar-se técnico, adquirir (por meio de outra Instituição) a certificação de ensino médio ou ser aprovado para o ensino superior via Exame Nacional do Ensino Médio (ENEM).

Cabe destacar que nos cursos integrados o aluno possui matrícula única, devendo ser aprovado nas disciplinas técnicas e propedêuticas para obtenção do certificado de conclusão (Brasil, 1996b). Assim, para concluir apenas o ensino médio, desconsiderando a formação técnica, o aluno precisa se desvincular da Instituição.

Sobre o ENEM, destacamos que no período de 2012 a 2016 era possível aos participantes solicitarem a obtenção de certificado de conclusão do ensino médio ou a declaração parcial de proficiência, se atendido todos os requisitos. Atualmente a certificação é obtida pelo Exame Nacional para Certificação de Competências de Jovens e Adultos (Encceja), devendo o interessado atender aos requisitos que o tornam apto para realizar o Exame (Brasil, 2020b, 2020c).

A respeito das expectativas, Rosales (2019) valendo-se das teorias de Bernard Charlot e Paulo Freire, enfatizou a importância da escuta e do diálogo. Isso porque os envolvidos no processo de ensino precisam estar atentos para acolher e propiciar escutas que busquem, além da aprendizagem, a permanência. De igual modo, Feitosa (2018) salientou a importância de um fazer pedagógico que considere a escuta e a acolhida do discente garantindo a permanência e o êxito.

Verifica-se nas propostas de intervenção a importância de se identificar o perfil dos discentes para realizar o 
acompanhamento de desempenho, bem como estabelecer ações e práticas de combate à evasão escolar condizentes com a realidade diagnosticada. Além disso, é necessário o envolvimento de todos os membros da comunidade escolar para a efetivação das ações e eliminação dos motivadores da evasão escolar.

\section{Considerações Finais}

Buscou-se neste estudo analisar os trabalhos de pós-graduação stricto sensu visando apresentar os fatores que motivaram o fenômeno da evasão escolar nos cursos técnicos integrados ao ensino médio da Rede Federal, bem como a proposição de intervenções de enfrentamento a esse fenômeno.

Destacam-se na identificação dos fatores motivacionais aqueles de ordem individual: falta de adaptação à vida acadêmica, desencanto ou desmotivação com o curso escolhido, pouca capacidade de aprendizagem e habilidade de estudo. Nos aspectos de ordem interna foram identificadas questões didático-pedagógicas e gestão acadêmica do curso. No aspecto de ordem externa evidenciou-se a conjuntura econômica e social.

As propostas de intervenção atuam no âmbito pedagógico e administrativo e demandam por comprometimento de toda a comunidade escolar para sua aplicabilidade. As intervenções, em sua maioria, concentram-se na identificação do perfil dos discentes para a realização de ações de acolhida e acompanhamento do desempenho escolar.

Para Rosa e Aquino (2019, p. 9) "o primeiro passo antes de se elaborar qualquer estratégia de enfrentamento, é conhecer bem o problema, porque sem conhecê-lo com propriedade, corre-se o risco de se colocar em prática estratégias que não surtirão nenhum efeito". Isto é, o diagnóstico e identificação dos fatores motivacionais da evasão escolar são necessários para o direcionamento das intervenções.

Nesse sentido, considerando a complexidade da evasão escolar, não se pode afirmar que o desenvolvimento das intervenções está diretamente relacionado à alteração nas taxas de evasão, deve-se investigá-las sobre e em conjunto com determinados contextos. Ademais, conforme exposto na "Nota Informativa 138", existem experiências desenvolvidas pelas Instituições que atuam sobre os fatores motivacionais da evasão e que não são divulgadas e, por isso, se faz necessário a adoção de ações sistemáticas e Institucionalizadas (Brasil, 2015).

Por fim, sugere-se a realização de diagnósticos periódicos para analisar as alterações nas motivações e nas taxas de evasão escolar, repensar as práticas e os ritos Institucionais, bem como dar publicidade aos resultados destas pesquisas a fim de subsidiar a continuidade dos estudos.

Recomenda-se para os trabalhos futuros a investigação com recorte de análise de regiões, tendo em vista a diversidade regional presente em nosso País, assim como estudos comparativos dentre os eixos dos cursos, verificando se há discrepâncias entre os territórios e as áreas de formação.

\section{Referências}

Almeida, M. D. B. de. (2019). Permanência e êxito no ensino médio integrado do IFG Uruaçu: orientações para qualificação e acompanhamento de estudantes. 225 fls. Dissertação (Mestrado em Ensino na Educação Básica) - Universidade Federal de Goiás, Goiânia, Brasil. http://repositorio.bc.ufg.br/tede/handle/tede/9380.

Bourdieu, P. \& Passeron, J-C. (2008). A Reprodução: Elementos para uma teoria do sistema de ensino. (2a ed.), Vozes.

Brasil (1996a). Comissão Especial de Estudos sobre a Evasão nas Universidades Públicas Brasileiras - ANDIFES/ABRUEM/SESu/MEC. Diplomação, Retenção e Evasão nos Cursos de Graduação em Instituições de Ensino Superior Públicas. Brasília, DF: MEC, 35 p. http://www.andifes.org.br/wpcontent/files_flutter/Diplomacao_Retencao_Evasao_Graduacao_em_IES_Publicas-1996.pdf.

Brasil (1996b). Lei no 9.394, de 20 de dezembro de 1996. Estabelece as diretrizes e bases da educação nacional. Diário Oficial da União, Brasília, DF, 23 dez. http://www.planalto.gov.br/ccivil_03/leis/19394.htm.

Brasil (2008). Lei n 11.892 , de 29 de dezembro de 2008. Institui a Rede Federal de Educação Profissional, Científica e Tecnológica, cria os Institutos Federais de Educação, Ciência e Tecnologia, e dá outras providências. Diário Oficial da União, Brasília, DF, 30 dez. http://www.planalto.gov.br/ccivil_03/_ato20072010/2008/lei/l11892.htm. 
Brasil (2013). Tribunal de Contas da União. Acórdão $n^{\circ}$ 506/2013 - TCU Plenário, de 13 de março de 2013. Brasília, DF: TCU, 13 mar., 64 p. https://www.lexml.gov.br/urn/urn:lex:br:tribunal.contas.uniao;plenario:acordao:2013-03-13;506.

Brasil (2014). Ministério da Educação. Documento orientador para a superação da evasão e retenção na Rede Federal de Educação Profissional, Científica e Tecnológica. Brasília, DF: MEC. 52 p. http://r1.ufrrj.br/ctur/wp-content/uploads/2017/03/Documento-Orientador-SETEC.pdf.

Brasil (2015). Ministério da Educação. Nota Informativa número 138/2015/DPE/DDR/SETEC/MEC. Brasília, DF: MEC, 8 p. http://200.19.248.10:8002/professores/\%23DEPARTAMENTO\%20DE\%20ENSINO/PERMANENCIA\%20E\%20EXITO/2015\%20Nota\%20Informativa\%20 n\%C2\%B0\%20138\%20_2015_DPE_DDR_SETEC_MEC-1.pdf.

Brasil (2020a). Ministério da Educação. Plataforma Nilo Peçanha: Ano Base 2017, 2018 e 2019. Brasília, DF: MEC. http://plataformanilopecanha.mec.gov.br.

Brasil (2020b). Instituto Nacional de Estudos e Pesquisas Educacionais Anísio Teixeira. Certificação do Ensino Médio. Brasília, DF: MEC. http://portal.inep.gov.br/certificacao-ensino-medio.

Brasil (2020c). Ministério da Educação: EnccejaMEC. http://portal.mec.gov.br/encceja.

Dore, R. \& Lüscher, A. Z. (2011). Permanência e evasão na educação técnica de nível médio em minas gerais. Cadernos de pesquisa. 41 (n¹44), $772-789$. https://www.scielo.br/scielo.php?script=sci_arttext\&pid=S0100-15742011000300007\&lng=pt\&tlng=pt.

Dourado, A. M. de S. (2016). Educação profissional no Instituto Federal de Educação Ciência e Tecnologia da Bahia: análise dos fatores intraescolares da evasão como base para criação do observatório pedagógico institucional no Campus de Irecê. 121f. Dissertação (Mestrado em Gestão e Tecnologias Aplicadas à Educação), Universidade do Estado da Bahia, Salvador. https://sucupira.capes.gov.br/sucupira/public/consultas/col eta/trabalhoConclusao/vie wTrabalhoConclusao.jsf?popup=true\&id_trabalho=4241771.

Feitosa, E. L. N. F. (2018). A permanência de alunos dos cursos de ensino médio integrado do Instituto Federal do Sertão Pernambucano Campus Serra Talhada: possibilidades e desafios. 170 f. Projeto de intervenção (Mestrado Profissional em Educação, Currículo, Linguagens e Inovações Pedagógicas) Faculdade de Educação, Universidade Federal da Bahia, Salvador. http://repositorio.ufba.br/ri/handle/ri/28812.

Gil, A. C. (2010). Como elaborar projetos de pesquisa. (5a ed.), Atlas.

Jordan, W. A.; Lara, J. \& Mcpartland, J. M. (1996c). Exploring the causes of early dropout among race-ethnic and gender groups. Youth and Society. 28, 6294.

Martins, G. de A. \& Theóphilo, C. R. (2016). Metodologia de investigação científica para ciências sociais aplicadas. (3a ed.), Atlas.

Medeiros, A. V. G. C. de. (2018). Água mole em pedra dura, tanto bate até que fura: estratégia de enfrentamento da evasão escolar no IF campus Ouricuri PE. 204 f.. Projeto de Intervenção (Mestrado Profissional em Educação) - Faculdade de Educação, Universidade Federal da Bahia. Faculdade de Educação, Salvador. http://repositorio.ufba.br/ri/handle/ri/27894.

Rosa, A. H. \& Aquino, F. J. A. de (2019). A evasão escolar na educação profissional técnica de nível médio: um olhar profundo sobre dois grandes vilões - a ausência de informações e a falta de identidade do ensino técnico. Research, Society and Development. 8 (7). Universidade Federal de Itajubá, Brasil. http://www.redalyc.org/articulo.oa?id=560662198041.

Rosales, G. F. (2019). Evasão e permanência em Educação Profissional e Tecnológica: um estudo a partir dos cursos técnicos integrados do IFSul Câmpus Camaquã. 62f. Dissertação (Mestrado em Educação Profissional e Tecnológica) - Instituto Federal de Educação, Ciência e Tecnologia, Charqueadas. https://sucupira.capes.gov.br/sucupira/public/consultas/coleta/trabalhoConclusao/viewTrabalhoConclusao.jsf?popup=true\&id_trabalho=7837322.

Santos, M. F. P. (2017). Evasão e reprovação escolar nos cursos integrados do IFBA campus Eunápolis. 218f. Dissertação (Mestrado Profissional em Educação) - Universidade Estadual de Santa Cruz, Ilhéus. https://sucupira.capes.gov.br/sucupira/public/consultas/coleta/trabalhoConclusao/v iewTrabalhoConclusao.jsf?popup=true\&id_trabalho=6237075.

Souza, T. R. de A. (2015). Estudo das relações entre a permanência no ensino técnico e a assistência estudantil no IFTM - Campus Paracatu. 147 p. Dissertação (Mestrado - Mestrado Profissional em Educação) - Universidade de Brasília, Brasília. https://repositorio.unb.br/handle/10482/19075.

Veiga, C. R. (2016). Fatores predominantes da evasão escolar no ensino médio integrado: uma proposta de estratégia de prevenção para o CEFET/RJ. $102 \mathrm{f}$. Dissertação (Mestrado em Sistema de Gestão) - Escola de Engenharia, Universidade Federal Fluminense, Niterói. https://app.uff.br/riuff/handle/1/4107. 